\title{
Analysis on the Marketing Strategy of Commercial Bank's Network Environment from the Financial Direction
}

\author{
Xiangning $\mathrm{Mu}$ \\ Northeast University of Finance and Economics, Dalian, China
}

\begin{abstract}
With the continuous development of social economy, the business in the field of finance on the Internet is also developing, which is greatly changing the traditional financial system in China. Internet finance has also once become a buzzword in the field of finance. on the one hand, this phenomenon can facilitate the economic life of the nation. On the other hand, it also caused an impact on the traditional offline financial business, especially commercial banks, etc., The commercial banks have urgent need to change the traditional marketing strategy. This paper suggests a new marketing strategy for commercial banks that is in line with the new online environment. Also, this paper analyzes commercial banks from the financial direction and discusses their marketing strategies in the new online environment.
\end{abstract}

Keywords: Internet Finance; Commercial Banks; Marketing Strategies.

\section{Introduction}

This financial development direction with strong characteristics of the times fully reflects the characteristics of "freedom, equality and speed" of the Internet, and gives new meanings to payment, financial management through the Internet and mobile communication. Through the Internet and mobile communication, it gives new meanings to payment, financing and finance, and realizes a series of financial activities with low cost and no intermediary. At the same time, finance in the network environment is largely virtual and often exists in electronic form, and financial transaction activities are gradually networked, giving birth to many unique commercial bank financial products and services. Undeniably, commercial banks have both advantages and shortcomings in the process of transformation, and opportunities and challenges coexist in the era. The financial direction of commercial banks must adapt to the new features of the network environment in a timely manner, and improve marketing strategies in the network environment.

\section{The Financial Influence of Commercial Banks in the Network Environment}

\subsection{The Financial Payment Intermediary Function Gradually Weakened}

In the traditional commercial banking development process, financial institutions carry a very important intermediary role, which is an important platform to connect customers and funds. However, with the rapid development of the Internet network, Internet finance has gradually formed a more complete system. Internet banking payments, mobile payments and other methods have greatly simplified the way customers pay, through a variety of apps with financial management functions such as Alipay, CaiPay, etc., The process of fund transfer no longer has to go through the intermediary procedures of commercial banks to handle. Under the premise of having the ability to independently dispose of money, customers independently deal with their money easily and freely on the internet. With the ability to control their own money, customers can make payments, transfer funds, and manage their finances. Although the intermediary function of commercial banks is still the mainstream for large amount of funds, it can be seen that a large amount of small amount of funds are being absorbed by the Internet third-party platforms, and the market share of commercial banks is decreasing, and the financial intermediary function of commercial banks is being gradually weakened. 


\subsection{Change of Profit Model}

Traditional commercial banks mostly make profits through the profit difference between deposits and loans, but the Internet makes a large amount of information flood into the hands of everyone who uses the Internet platform, especially the third-party financial platform, which has a great impact on the traditional commercial banks' mode of collecting savings at low interest rates. Platform for digital savings, which makes most of the commercial bank customers are lost and commercial banks are facing a large loss of deposit funds. In addition, the lending business was one of the main incomes of commercial banks in the past, but the emergence of a large number of third-party "low-cost, fast and efficient" lending platforms on the Internet platform attracts many customers with lending intentions, which makes the lending business part of the bank's profit model face a series of impact. Users are faced with more choices, and commercial banks are limited by the traditional marketing model, which is no longer attractive in this new network environment.

\subsection{Changes in the Service Model}

In the environment of Internet finance, the service model of commercial banks has to make changes. Internet technology is seen as a necessary technology for commercial banks not to be eliminated by the times. Internet companies can integrate and analyze customer information on the network platform through many new data mining and analysis technologies, so as to evaluate and identify credit qualifications, determine independently whether customers are qualified to apply for credit services, make loans and receive payments, etc., Hence, with internet technology, commercial banks can provide personalized financial services. Then, the information is transferred to the data terminal to establish the individual's bank credit file which could be fully useful. The information integration and independent determination of big data have many advantages over the traditional human audit and mortgage offsetting, and also largely reduce the risk of bank credit, so the service mode of commercial banks should also adapt to this trend of big data technology development, and the service mode is facing a change.

\subsection{Promote the Transformation of Commercial Banks}

The development of the Internet provides a lot of giving for the transformation of commercial banks. Commercial banks should actively cooperate with Internet enterprises, which collect customers' information through channels such as e-commerce, third-party payment and social networks. With such information, commercial banks can collect and organize customers' information database. Then, by the information analysis technology of big data, it can let the party who needs funds and the party who issues funds complete the matching of information and pricing in a shorter time, which can make commercial banks business more. This can improve the service efficiency and quality of commercial banks, thus effectively optimizing the allocation of bank resources, reducing the consumption of human and material resources generated by commercial banks in various links, providing more accurate matching services, and enabling Internet technology to empower commercial banks in the new network era.

\section{The Problems of Marketing Strategies of Commercial Banks in the Network Environment Form the Financial Direction}

\subsection{Insufficient Innovation of Financial Products}

At the time of continuous construction of socialist modernization and deepening reform of economic system in China, commercial banks need to continuously enhance their core competitiveness and obtain the long-term momentum of good development in order to get sustainable and continuous development of commercial banks if they want to take a firm foothold in the market and not be eliminated by the society. However, for the financial products of commercial banks, many commercial banks are at a loss in the face of the changing environment of network marketing and 
public psychology, and the strength of product innovation is not enough, and it can even be said that the financial innovation of commercial banks is relatively lagging behind. On the one hand, in the financial direction, the financial products of commercial banks do not have characteristics, and there are products that "as the same". Many commercial banks do not innovate their financial products and do not realize the importance of product innovation and special financial products under the drastic changes of the network environment, but simply imitate and follow the mainstream of financial products in the commercial banking industry. There is homogenization in business philosophy and development strategy. On the other hand, the financial products of commercial banks lack personalization. The continuous improvement of living standards makes each citizen have unique financial product needs, but in terms of product supply of commercial banks, and the products are limited by the insufficient integration with the Internet, many commercial banks lack the appropriate motivation to meet the personalized needs of customers. Overall, compared to other internet companies, commercial banks lack sufficient advantages in financial products.

\subsection{Inadequate Pricing System}

Pricing system is a very important part of commercial banks' marketing process, which are directly related to commercial banks' profit income, so the development of a perfect pricing system is very important to improve the marketing model of commercial banks and develop business strategies. On the one hand, there is a very urgent need to improve the pricing system. The weakened intermediary position of commercial banks and the loss of large amounts of capital, as mentioned above, have directly led to the adverse impact on the profits and core capital of commercial banks. And under the policy of national economic development requiring high-quality growth rather than just speeding up our ecomony, there are potential problems such as the increase of non-performing rates in the marketoriented network environment of banks. In the current situation, there is a lack of pricing awareness in the pricing system of banks, mainly due to a number of existing policy factors, and banks themselves are not sufficiently well grounded in the commercial pricing direction to consistently be able to develop clear and well-defined and market-based pricing strategies. In addition, because pricing strategies need to be supported by a large amount of information data, commercial banks need to develop a perfect pricing model and constantly revise it, which is also a reflection of the lack of awareness of commercial banks in terms of database. In some of the commercial banks pricing model and method development, the database is not sound enough, which leads to some commercial banks pricing system lacks a certain data base. In pricing system, there is naturally not accurate data analysis. Hence, in the provision of personalized services and predict the market response, commercial banks' sensitivity to customers is not enough.

\subsection{Inadequate Marketing Channels}

On the one hand, many commercial banks in China emerged from the 1990s with the development of society, such as online banking. Through the continuous development of society, the marketing channels of commercial banks are constantly developing in the direction of diversified marketing. In the process of practical development in recent years, commercial banks have developed online banking, telephone banking, mobile banking and other online marketing channels, combined with offline outlets to carry out comprehensive services. However, it is predictable that commercial banks still focus on marketing in the down-line channels, mainly in the off-line bank branches to carry out some business marketing, which did not pay enough attention to online marketing. Also, the comprehensive use of online marketing resources is not high enough, the marketing channels are narrow. On the other hand, the marketing channel model of banks is not perfect, and the unity and sharing of information between various marketing outlets and online channels are still lacking, so many customers often have time lag and conversion difficulties when handling business in commercial banks. 


\subsection{Insufficient Variety of Promotion Methods}

In the Internet network environment, the promotion concept of commercial banks also needs to be integrated with the Internet. Commercial banks change the traditional promotion concept. Commercial banks should look at the innovative design and promotion of financial products with Internet thinking. Also, in the marketing strategy of commercial banks, it must be combined with the actual database and at the same time carry out diversified promotion with the help of a variety of technical network operation methods. One of the reasons for the existence of this phenomenon is that the financial product design and strategic positioning is not innovative and lacks precise positioning of customer needs. On the other hand, the content of marketing lacks novelty. Many commercial banks do not pay enough attention to online operation and promotion in their marketing strategies, which made customers have a single way to learn about information and are not very interactive in the actual participation process, so that old customers are retained and new customers are not attracted.

\section{Improvement Direction of Commercial Banks in the Network Environment Marketing Strategy from the Financial Direction}

\subsection{Commercial Banks Should Increase Financial Product Innovation}

In the Internet network environment, the intermediary status of commercial banks is weakening. Regarding with the personalized needs of customers are rising, every financial product should be supposed to serve the needs of customers, and so is Internet finance, which attaches great importance to the experience of customers for financial products. Therefore, commercial banks should increase the innovation of financial products and design suitable financial products with the important principle of customer experience as the center. Also commercial banks should continuously collect customers' opinions and provide information basis for customer demand analysis and product innovation direction by using big data technology as an auxiliary means. Commercial banks have unique advantages in the process of transformation, as they are usually established for a long time and have accumulated huge customer resources. In the new Internet environment, they are bound to be able to create a unique data resource base through the analysis of big data technology to serve the development and marketing of financial products, achieve accurate positioning of financial products, and be able to provide personalized services. In addition, commercial banks must develop appropriate development strategies based on the actual marketing situation to avoid homogenization to the greatest extent possible. Only by doing this, commercial banks can truly get long-term sustainable development in the market-oriented commercial banking competition process.

\subsection{Improve the Ability of Differentiated Marketing}

Pricing is one of the most core profits of commercial banks, so commercial banks must establish unique business models and methods to enhance differentiated marketing capabilities to meet the challenges of the market. Commercial banks must assess the risk of customers through their creditworthiness and classify customers, provide more refined investment and financing services for high-contributing customers, create customized products and risk control solutions, and provide a series of services in the industry chain. For the mass customers, they can create bulk products that meet the needs of customers through lower costs to meet the financial needs of customers at different levels. In terms of pricing strategy, commercial banks also need to differentiate pricing for customers with different contribution levels and adopt different preferential policies. Through differentiated pricing marketing strategies, commercial banks can maximize customer retention and improve customer retention and loyalty, thus being able to reduce the phenomenon of customer churn caused by third-party Internet platform products. 


\subsection{Integrate Bank Marketing Channel Resources and Increase Interactive Marketing Capability with the Help of Internet Platform}

On the one hand, with the continuous development of social network platforms, many commercial banks' customers are also influenced by the network environment in terms of payment methods, financing methods and lending platforms, etc. Customers also tend to conduct financial behaviors through safe Internet platforms. Commercial banks should fully explore the financial business development of the Internet platform, no longer limited to the traditional data boundaries, and also fully combine the advantages of the Internet. With the help of Internet big data analysis technology, commercial banks can create a platform for diversified interaction, enhance the interaction and understanding with customers, and broaden the profit channels of commercial banks. At the same time, commercial banks should strengthen the construction of their own marketing channels, improve the construction of their owned online banking and mobile banking, promote the intelligence of their outlets, integrate online and offline marketing information resources, better integrate with the current trend of Internet finance, and broaden the business and financial service channels of banks.

On the other hand, commercial banks must pay attention to the new financial industry that is constantly developing, pay more attention to customer interaction and communication, change the problem of a single promotional model, increase marketing means and improve the degree of customer interaction in the marketing process of commercial banks. To achieve better development in the environment of Internet finance, commercial banks must develop a new marketing model such as online marketing and combine it with traditional offline marketing so as to meet the needs of customers of different ages, such as young people and the elderly, and improve customer experience. While promoting offline promotions, customers are guided to operate online so as to achieve the organic integration of online and offline and improve the bank's interactive marketing capabilities. At the same time, they should also make full use of advertising, public relations, business promotion and other means, so that the promotion work can be carried out comprehensively.

\section{Conclusion}

In summary, with the continuous development of Internet technology, Internet finance has become an inevitable development trend for commercial banks. The impact brought by the network environment to commercial banks is very obvious, the financial payment intermediary function is gradually weakened, the profit model has changed, the service model has changed, which can lead to the transformation of commercial banks. However, in the network environment, commercial banks in the financial direction of the development of deficiencies, such as financial product innovation is not enough, the pricing system is not perfect, marketing channels are not perfect promotion methods are not diverse enough. To obtain long-term sustainable development momentum, commercial banks should increase financial product innovation, enhance differentiated marketing capabilities, integrate bank marketing channel resources with the Internet platform, increase interactive marketing capabilities, and fully integrate with the Internet platform.

\section{References}

[1] Miao Aoran, Xiao Jianbin, Hou Qinghui, Wang Jun. Research on the Transformation Strategy of Commercial Bank Outlet based on New Retail Concept [J]. Journal of Jilin Financial Research, 2021, (02): 43-48.

[2] Guo Jie. Measures for the development of intermediate business of commercial banks in the context of Internet finance[J]. Accounting Learning, 2021,(07):169-170.

[3] $\mathrm{Lu} \mathrm{Lu}$. Research on the marketing strategy of commercial banks in digital transformation[J]. Marketing Industry, 2021, (22):93-94.

[4] Liu Yang. Research on the precise marketing strategy of commercial banks in the era of big data[J]. Business News, 2021, (26), 100-102. 
Volume 15 (2021)

[5] Fu Kunru. Introduction to marketing research of commercial banks in China [J]. Time Finance, 2021, (03), 30-32. 